\title{
WORKING MEMORY CAPACITY AND L2 SPEECH PERFORMANCE IN PLANNED AND SPONTANEOUS CONDITIONS: A CORRELATIONAL ANALYSIS
}

\section{CAPACIDADE DE MEMÓRIA DE TRABALHO E DESEMPENHO ORAL EM L2 EM CONDIÇÕES PLANEJADAS E ESPONTÂNEAS: UMA ANÁLISE CORRELACIONAL}

\section{Maria da Glória Guará-Tavares*}

\begin{abstract}
The present study is part of a larger scale research that investigates the relationship between working memory capacity, pre-task planning, and L2 speech performance. The aim of the study was to analyze 1) the relationship between working memory capacity and L2 speaking performance in spontaneous conditions and 2) the relationship between working memory capacity and L2 speaking performance in planned conditions. L2 speech performance was analyzed in terms of fluency, accuracy and complexity. Results indicate a complex relationship between working memory capacity and L2 speech performance. The correlational analysis reveals that a) there are significant correlations between working memory capacity and accuracy in spontaneous conditions; b) there are significant correlations between working memory capacity, fluency and complexity in planned conditions. The results are discussed according to Engle, Kane, \& Tuholski (1999), Fortkamp (1999, 2005), Foster \& Skehan (1996), Menhert (1998) e Yuan \& Ellis (2003).
\end{abstract}

Keywords: working memory; L2 speech production; planning.

\section{RESUMO}

O presente estudo é um recorte de uma pesquisa de maior escala que investiga a relação entre capacidade de memória de trabalho, planejamento pré-tarefa e desempenho oral em L2. O objetivo do presente estudo foi analisar a relação entre 1) capacidade de memória de trabalho e desempenho oral em condições espontâneas e 2) capacidade de memória de trabalho e desempenho oral em condições planejadas. O desempenho oral foi avaliado através de medidas de acurácia, fluência e complexidade da fala (Skehan 1996, 1998). Os resultados indicam uma complexa relação entre capacidade de memória de trabalho e desempenho oral em L2, uma vez que a análise correlacional demonstra que a) há correlações significativas entre capacidade de memória de trabalho e acurácia em condições espontâneas; b) há correlações significativas entre capacidade de memória de trabalho, fluência e complexidade em condições planejadas. Os resultados são discutidos com base

\footnotetext{
* UFC, Ceará (CE), Brasil. g.tavares123@hotmail.com
} 
em Engle, Kane, e Tuholski (1999), Fortkamp (1999, 2003), Foster \& Skehan (1996), Menhert (1998) e Yuan \& Ellis (2003).

Palavras-chave: memória de trabalho, produção oral em L2, planejamento.

\section{INTRODUCTION}

Skehan (1996) proposes a framework for the implementation of taskbased instruction. Within the task-based approach, the main assumption is that "psychological factors and processing conditions are highly relevant to second language learning and second language performance" (SKEHAN, 1998, p. 93). In this sense, three issues are central for task analysis and implementation (SKEHAN, 1996). First, attention and noticing are essential for L2 learning (SCHMIDT, 1990). Second, attentional resources are limited (VAN PATTEN, 1990, 1996). Third, in L2 learning and performance, learners draw upon a dual-mode processing system consisting of the exemplar-based system and the rule-based system (SKEHAN, 1998). The exemplar-based system emphasizes meaning and regards learning in terms of the accumulation of chunks. The rule-based system emphasizes analyzability leading to the development of an open form-oriented system, according to which learning is related to growth, change, and complexity of the underlying system.

Interestingly, Feldman-Barrett, Turgade, and Engle (2004) also acknowledge a dual-mode processing system: in associative processing (exemplar-based), information is processed automatically. Thus, associative processing is not under the constraints of working memory limitations. On the other hand, they claim that rulebased processing is subjectively effortful, strategically coordinated to individuals' goals. Thus, rule-based processing is more harshly under the constraints of working memory limitations.

In his framework, Skehan (1996) proposes a cycle of tasks which encompasses pre, mid, and post task activities. Pre-task activities are aimed at enhancing task performance. Mid-task activities focus on the ways in which the tasks are done and are aimed at balancing, reducing or enhancing task difficulty in order to balance learners' attention among the goals of fluency, accuracy, and complexity. Posttasks activities are aimed mainly at raising awareness for a focus on form. Pre-task activities (e.g., planning) are used to introduce new language, mobilize language, recycle language, ease processing load, and to push learners to interpret the task in more demanding ways (SKEHAN, 1998).

Based on what has been said, pre-task planning is originally a type of activity which belongs to the pre-task stage in Skehan's (1996) framework to task-based 
instruction. Due to a growing body of research on planning, it has evolved into an area of inquiry in its own right and has become "a burgeoning area of research within task-based language learning" (ORTEGA, 2005, p.77).

A considerable body of research has examined the impact of planning on L2 performance (FOSTER \& SKEHAN, 1996; MEHNERT, 1998; ORTEGA, 1999, 2005; YUAN \& ELLIS, 2003; GUARÁ-TAVARES, 2009, among others). In general, studies have shown a positive impact of planning on L2 performance. Several studies have shown that planning leads to gains in fluency ${ }^{1}$ (FOSTER \& SKEHAN, 1996; MEHNERT, 1998; ORTEGA, 1999). Planning also leads to gains in accuracy, although results have been more mixed in this respect (ELLIS, 1987; MEHNERT, 1998; ORTEGA, 1999; FOSTER \& SKEHAN, 1996). Finally, studies have also shown that planning enhances complexity (CROOKES, 1989; FOSTER \& SKEHAN, 1996; MEHNERT, 1998; ORTEGA, 1999; YUAN \& ELLIS, 2003).

One intriguing recurrent outcome of the studies on the impact of planning on L2 performance is the evidence of attentional trade-off effects among the goals of fluency, accuracy, and complexity. Foster and Skehan (1996), Menhert (1998), as well as Yuan Ellis (2003) and Guará-Tavares (2009) discuss results of their studies in terms of an attentional model of learning and performance. In this sense, these researchers propose that there are trade-off effects among the goals of fluency, accuracy, and complexity in the context of the use of learners' limited capacity attentional resources.

For the purposes of the current study, the perspective taken is that working memory resources are attentional. In the present study, working memory is defined as "a system consisting of those long-term memory traces above a threshold, the procedures and skills to achieve and maintain that activation, and limited-capacity, controlled attention" (ENGLE, KANE \& TUHOLSKI, 1999, p. 102).

Despite the fact that researchers in task-based planning (e.g. FOSTER \& SKEHAN, 1996; MENHERT, 1998; YUAN \& ELLIS, 2003) explain results of studies in terms of learners' limited capacity attentional resources, individual differences in working memory capacity have not been taken into account in any of these studies (e.g. FOSTER \& SKEHAN, 1996; MENHERT, 1998; YUAN \& ELLIS, 2003,) as a feasible variable for affecting learners' performance under planning conditions.

Although planning is a means of helping learners overcome limitations in working memory and improving performance (ELLIS, 2005), it seems reasonable

\footnotetext{
1 According to Skehan $(1996,1998)$, fluency is related to the temporal aspects of speech production; accuracy is related to grammatical correctness; complexity is related to language elaboration (e.g., subordination).
} 
to argue that individual differences in working memory capacity may still emerge in L2 performance under planning conditions. Planning is a problem solving activity (ELLIS, 2005; D'ELY, 2006; HAMBRICK AND ENGLE, 2003), and it seems to assist performance by triggering a range of strategic, metalinguistic, and metacognitive behaviors (Ortega, 2005). It seems reasonable to argue that one's ability to engage in such strategic behaviors successfully may to some extent explain benefits achieved from planning. Since individuals with higher capacity tend to be more strategic (McNamara \& Scott, 2001; Hambrick and Engle, 2003), individual differences in working memory capacity may reflect differences on how successful one is in the process of planning.

In addition to that, the benefits of planning on performance may also depend on the ability to actually retrieve what was planned and implement it into online performance (ORTEGA, 2005). According to Rosen and Engle (1997), working memory plays a crucial role in retrieval, that is to say, individuals with higher capacity tend to retrieve information more effectively during the performance of complex cognitive tasks.

Bearing that in mind, working memory capacity may play a role on how successfully one is in engaging in planning as well as on how effectively one may retrieve and implement what was planned into online performance. In order to scrutinize whether individual differences in working memory capacity emerge in L2 oral performance under planning conditions, the present study sets out to examine whether working memory capacity correlates with L2 speech performance under no planning and planning conditions.

\section{REVIEW OF THE LITERATURE}

\subsection{Models of $L 1$ and $L 2$ speech production}

Levelt's (1989) model of L1 speech production has four specialized components, which underlie the speech production: the conceptualizer, the formulator, the articulator, and the speech comprehension system. These components work in a highly automatic way, and automaticiy is what allows the components to work in parallel, which is, in turn, "a main condition for the production of uninterrupted speech" Levelt (1989, p. 2).

De Bot (1992) made a few adaptations to Levelt's (1989) model in order to account for L2 speech production. The first assumption of De Bot's (1992) 
model is that the speaker has, first of all, to decide what language to speak. This decision takes place in the conceptualizer. As far is the formulator is concerned, De Bot (1992) proposes that it is language-specific, thus, different procedures are applied to the grammatical encoding of L1 and L2 speech. Finally, De Bot (1992) suggests only one articulator for both languages. By assuming only one articulator L1 interferences in L2 can be explained.

On the one hand, L1 speech production is highly automatized. Poulisse (1999), on the other hand, postulates that: (a) L2 knowledge is not complete, (b) L2 is more hesitant, has shorter sentences and slips of the tongue, (c) L2 may carry traces of L1 and (d) proficient speakers can keep one or more languages apart when they wish to do so. Thus, the high degree of automatization in L1 does not apply to L2. For this reason, in many circumstances, L2 learners may need to creatively construct plans for communicative situations since ready-made chunks may not be available, and this activation of procedures demands high degrees of cognitive control (MEHNERT, 1998). These control processes take place under a limited capacity cognitive system, working memory.

\subsection{Working memory and L2 speech performance}

As briefly stated in the introduction, the perspective taken in the present study is that working memory resources are attentional, that is to say, I take Engle's (1999) attention-view perspective of working memory capacity. Engle et al. (1999) view working memory as a cognitive system comprising (a) a store in the form of long-term memory traces active above a threshold, (b) processes for achieving and maintaining this activation, and (c) controlled attention. Nevertheless, when they refer to 'working memory capacity', it is the limited capacity of the element of controlled attention that is being referred to. More specifically, for Engle and his associates the term working memory capacity refers to "attentional processes that maintain task-relevant information activated in an accessible state, or to retrieve that information under conditions of interference, conflict, and competition" (KANE, CONWAY, HAMBRICK, \& ENGLE, 2007, p. 23).

Daneman and Green (1986) developed the Speaking Span Test (hereafter SST) in order to investigate whether WM capacity would be a good predictor of learners' ability to use context to both comprehend and produce words in their L1. Daneman and Green (1986) tested whether there was a relationship between WM capacity and the ability to produce synonyms for words presented in context. They found a correlation between WM capacity scores and the synonym lexical test 
scores. Later, Daneman (1991) investigated whether WM capacity could account for individual differences in verbal L1 fluency.

Fortkamp (1999) expanded Daneman's (1991) study in order to investigate whether working memory would be a good predictor of L2 verbal fluency. Fortkamp (1999) also found significant correlations between WM capacity as measured by the SST and L2 speech rate in the speech generation task. Fortkamp (2000) investigated whether WM capacity would predict individual differences in L2 fluency, accuracy, complexity and weighted lexical density. Results indicated that individuals with higher working memory capacity tend to be more fluent, accurate and complexity and weighted lexical density. Results indicated that individuals with higher working memory capacity tend to be more fluent, accurate and complex in L2. Interestingly, the study provided evidence of trade-off effects since accuracy, fluency and complexity of speech tended to be achieved at the expense of weighted lexical density.

\subsection{Pre-task planning}

D'Ely (2004) argues that although planning is essentially a cognitive process which is inherent to the act of speaking, it evolves into a metacognitive process when it is used strategically by the learner. Therefore, D'Ely (2004) defines strategic planning as a problem-solving activity that provides learners the opportunity "to exert some control over what they know towards achieving gains in oral performance" (p.17).

To reiterate, planning is a problem solving activity, and according to Hambrick and Engle (2003), a problem is a goal which is not instantaneously achievable and whose most prominent feature is that although the initial state and the target are clear, how to convert the initial state into the target state is uncertain. Hambrick and Engle (2003) claim that problem solving activities require "the ability to maintain goals, action plans, and other task-relevant information in a highly activated and accessible state, and when necessary, to inhibit activation of irrelevant or distracting information" (p.179).

As mentioned in the introduction, several studies have investigated the impact of planning on L2 performance. In general, studies have shown a positive impact of planning on performance but gains do not seem to be achieved simultaneously to the same extent for the different aspects of performance- fluency, accuracy and complexity since these aspects compete for learners' limited capacity attentional 
resources (FOSTER AND SKEHAN, 1996; MEHNERT, 1998; GUARÁTAVARES, 2009).

\section{THE CURRENT STUDY}

Based on the preceding review, planning seems to assist performance by minimizing limitations in working memory capacity, however, it seems reasonable to argue that individual differences in working memory capacity would still emerge in performance under planning conditions. In order to scrutinize these issues and to expand the study by Guará-Tavares (2009), the current study sets out to answer two research questions:

1) Does L2 speech performance under spontaneous conditions significantly correlate with working memory capacity as measured by fluency, accuracy and complexity?

2) Does L2 speech performance under planned conditions significantly correlate with working memory capacity as measured by fluency, accuracy and complexity?

\section{METHOD}

Data collection of the present study was divided into three phases. The first phase was the selection of participants which aimed at controlling for proficiency level. Participants performed the proficiency trial task at the language laboratory, and all students of the same class did the task together (See GUARÁ-TAVARES, 2011, for a detailed description of the selection of participants). Due to participants' time constraints, the task used for selecting participants also served as the first sample of L2 speech performance under spontaneous condition.

The second phase consisted of the Speaking Span Test to measure participants' working memory capacity. Participants of the experimental and control groups carried out the speaking span test individually with the researcher in a computer lab. A training session on how to take the test took place before test performance itself.

The third phase of data collection consisted of the second narrative task. Participants of the control group carried out the second narrative task under the same condition as the first narrative task, that is to say, under a spontaneous 
condition. On the other hand, participants of the experimental group carried out the second narrative task under a planned condition, that is to say, students had 10 minutes to plan the oral task prior to actual performance. The focus of the present study is the analysis of participants' performance on the second narrative task, carried out under a spontaneous condition for the control group and under a planned condition for the experimental group.

\subsection{Context and participants}

The participants of the present study were 50 intermediate learners from the Letras ${ }^{2}$ Licenciatura, Letras Secretariado $^{3}$, and also from the Extracurricular Language Courses at Universidade Federal de Santa Catarina (UFSC). Participants of the Extracurricular Language courses were all undergraduate students at Universidade Federal de Santa Catarina from a variety of backgrounds. Out of the 50 participants, 30 were female, 20 were male, and their ages ranged between 18 and 29 years old. Participation was voluntary and no financial reward was given.

\subsection{The Speaking Span Test}

A version of Daneman and Green's (1986) Speaking Span Test was used. A training phase $(20$ words) preceded the testing phase (60 words). The test contained 60 unrelated words organized in three sets each of two, three, four, five and six words.

Each word was presented individually, on the middle line of a computer screen for one second. Participants were instructed to read each word aloud. At the end of each set, question marks appeared. These marks signaled the number of words that had to be stored and the number of sentences to be produced. Participants were instructed to use the words in the exact form and order they appeared to generate syntactically and semantically acceptable sentences, aloud, in English.

There were no restrictions concerning the length or complexity of the sentences produced. For instance, after being presented a set of three words: guy point - train, a participant produced the following sentences: "I am a guy", "what's your point?"; "The train was dirty". Participants' speaking span score was defined as the maximum number of words for which they could generate grammatically and semantically acceptable sentences in English.

2 Undergraduate Language Teaching and Literature program.

3 Undergraduate Bilingual Secretary program. 
Following Daneman (1991), in this study, participants' responses, which were recorded, transcribed and analyzed, generated two different speaking span scores: a speaking span strict score, when all the sentences the subject produced contained the target word in the exact form and order of presentation; and a speaking span lenient score, when credit was given for sentences that contained the target word in a form other than that of presentation (e.g., target word being 'guy' and the word in the sentence produced being 'guys'), and half credit was given to words recalled in a different order. No credit was given to ungrammatical sentences in terms of syntax and semantics.

\subsection{The speech generation tasks: 'there and then narratives'}

The two tasks used were both 'there-and-then' picture cued narratives (ROBINSON, 1995). In both tasks, participants had 50 seconds to look at the set of pictures and then put pictures away. Narrative tasks have been widely used in previous studies on task-based planning (D’ELY, 2006; ELLIS, 1987; FOSTER; SKEHAN, 1996; KAWAUCHI, 2005; ORTEGA, 1999) thus, allowing for comparison between the present study and previous ones in the field. The order of tasks was counterbalanced among participants for the purpose of controlling practice effects.

Participants of the control group carried out both tasks under a spontaneous condition. They were instructed to start telling their stories immediately after looking at the pictures for 50 seconds. On the other hand, participants of the experimental group were instructed to plan the second task for 10 minutes after looking at the pictures for 50 seconds. The pictures were removed from them before they started planning their task. The choice of 50 seconds for looking at the set of pictures aimed at minimizing planning as much as possible in the spontaneous condition. According to Mehnert (1998), one minute planning may be enough for gains in accuracy to take place. Thus, participants were given less than one minute to look at the set of pictures.

\subsection{Measures of $L 2$ speech performance}

The speech samples were analyzed in terms of fluency, accuracy, and complexity. These measures have been extensively used in studies investigating the effects of planning on L2 speech performance (FOSTER \& SKEHAN, 1996; MEHNERT, 1998; ORTEGA, 1999; YUAN \& ELLIS, 2003; among others). 
Fluency - as in Fortkamp (2000), speech rate unpruned was calculated by dividing the total number of semantic units (complete and partial words) produced by the total time in seconds (including pause time), the resulting figure was multiplied by 60 to express the number of semantic units per minute; speech rate pruned was calculated in the same way but excluding: (a) the words that were abandoned before completion, and (b) words that were immediately repeated (except words repeated for rhetorical purposes).

Number of silent pauses per c-unit was calculated by dividing the number of silent pauses in each subject's speech sample by the number of c-units, as in D'Ely (2006). Following Foster and Skehan (1996), and Mehnert (1998), a cut-off point of 1 second was considered optimal in determining silent pauses in L2 speech samples. Pauses were identified and measured using the computer software PRAAT ${ }^{\circledR}$ version 4.6.06. ${ }^{4}$ Percentage of total silent pausing time was calculated by dividing the total silent pausing time by the total time participants took to complete the task, the resulting figure was multiplied by 100 (D’ELY, 2006; FOSTER \& SKEHAN, 1996).

Accuracy - according to Skehan $(1996,1998)$, accuracy concerns form in the sense of error-free performance. It was operationalized in terms of number of errors per a hundred words and percentage of error-free clauses. Number of errors $^{5}$ per a hundred words was calculated by dividing participants' total number of errors by the total number of words produced and multiplying the result by 100 (FORTKAMP, 2000; MEHNERT, 1998). Percentage of error-free clauses was calculated by identifying the number of error-free clauses, which was then divided by the total number of clauses produced, and the resulting figure was multiplied by 100 (FOSTER; SKEHAN, 1996; MEHNERT, 1998).

Complexity - according to Foster and Skehan (1996), subordination is considered a satisfactory measure to assess complexity, which was measured by an index of subordination reflected by the number of clauses per c-unit. It was calculated by dividing the total number of clauses (dependent and independent) by the total number of c-units. The higher the index of subordination obtained the higher the complexity of the speech was.

\subsection{Data Analysis Procedures}

Participants' performance was analyzed in terms of fluency, accuracy and complexity. Working memory scores were calculated and Person Correlations were

4 This software allows the identification of the precise location and length of speech pauses.

5 The criteria for defining errors were based on American English norms since this is the English variety adopted by the textbooks used by the participants. 
carried out to check whether there was a relationship between measures of working memory capacity and measures of L2 speech performance.

\section{RESULTS AND DISCUSSION}

In this section, I will report and discuss results of the correlational analyses. Table 1 displays the correlations between working memory capacity and L2 speech performance under spontaneous conditions for the control group, and Table 2 displays the correlations between working memory capacity and L2 speech performance under planned conditions for the experimental group.

Table 1. Correlations Between Working Memory and Speech Performance under spontaneous conditions (Control group)

\begin{tabular}{|c|c|c|c|c|c|c|c|c|}
\hline & & SRU & SRP & PCU & TPT & ACCW & ACCC & COMP \\
\hline WML & Pearson Correlation & .032 & .038 & -.007 & .282 & $-.703^{* *}$ & $.740^{* *}$ & -.036 \\
\hline & Sig. (2-tailed) & .881 & .858 & .973 & .172 & .000 & .000 & .863 \\
\hline & $\mathrm{N}$ & 25 & 25 & 25 & 25 & 25 & 25 & 25 \\
\hline WMS & Pearson Correlation & .016 & .021 & .008 & .273 & $-.676^{* *}$ & $.696^{* *}$ & -.072 \\
\hline & Sig. (2-tailed) & .940 & .921 & .970 & .186 & .000 & .000 & .732 \\
\hline & $\mathrm{N}$ & 25 & 25 & 25 & 25 & 25 & 25 & 25 \\
\hline
\end{tabular}

Note. WML = working memory lenient scores; WMS = working memory strict scores; SRU $=$ speech rate unpruned $; \mathrm{SRP}=$ speech rate pruned $_{i} \mathrm{PCU}=$ number of pauses $/ \mathrm{c}$-unit $;$ TPT $=$ total percentage of pausing time, $\mathrm{ACCW}=$ number of errors $/ 100$ words $; \mathrm{ACCC}=$ percentage of error free clauses; $\mathrm{COMP}=$ number of clauses $/ \mathrm{c}$-unit $* * \mathrm{p}<.01$

Table 2. Correlations Between Working Memory and Speech Performance under planned conditions (Experimental group)

\begin{tabular}{|c|c|c|c|c|c|c|c|c|}
\hline & & SRU2 & SRP2 & PCU2 & TPT2 & ACCW2 & ACCC2 & COMP2 \\
\hline WML & $\begin{array}{c}\text { Pearson } \\
\text { Correlation }\end{array}$ & $.430^{*}$ & $.442^{*}$ & .159 & -.294 & -.371 & .229 & $.426^{*}$ \\
\hline & Sig. (2-tailed) & .032 & .027 & .448 & .154 & .068 & .271 & .034 \\
\hline & $\mathrm{N}$ & 25 & 25 & 25 & 25 & 25 & 25 & 25 \\
\hline
\end{tabular}




\begin{tabular}{|c|c|c|c|c|c|c|c|c|}
\hline WMS & $\begin{array}{c}\text { Pearson } \\
\text { Correlation }\end{array}$ & $.481^{*}$ & $.494^{*}$ & .146 & -.290 & -.335 & .223 & .345 \\
\hline & Sig. (2-tailed) & .015 & .012 & .485 & .160 & .102 & .284 & .092 \\
\hline & $\mathrm{N}$ & 25 & 25 & 25 & 25 & 25 & 25 & 25 \\
\hline
\end{tabular}

Note. WML = working memory lenient scores; WMS = working memory strict scores; SRU $=$ speech rate unpruned; $\mathrm{SRP}=$ speech rate pruned; $\mathrm{PCU}=$ number of pauses $/ \mathrm{c}$-unit; $\mathrm{TPT}$ $=$ total percentage of pausing time $\mathrm{ACCW}=$ number of errors $/ 100$ words; $\mathrm{ACCC}=$ percentage of error free clauses; COMP = number of clauses $/ \mathrm{c}$-unit $* \mathrm{p}<0.05$

I will address these results as follows. First, I will discuss the correlations between working memory capacity and L2 speech performance for the control group under spontaneous condition. Next, I will discuss results of the correlations between working memory and L2 speech performance for the experimental group under the planned conditions.

As shown in Table 1, there were significant correlations between working memory and accuracy as measured by number of errors per one hundred words and percentage of error free clauses in the performance of the control group. In other words, within the control group, higher spans made fewer errors per one hundred words and produced more error free clauses. These results corroborate previous results found in the literature (FORTKAMP, 2003; MIZERA, 2006).

If on the one hand, fluent speech performance implies automaticity, which encompasses managing all stages of speech production in an effective way so as to allow continuous speech in real time communication to take place, accurate speech performance, on the other hand, implies monitoring, which is considered a cognitively demanding process (LEVELT, 1989). Monitoring demands attentional control, in which the speaker attends to his/her own internal and overt speech (LEVELT, 1989). Therefore, what seems to account for the correlations between working memory capacity and accuracy is not mainly the ability to control attention during conceptualization, message construction, and formulation (as in the case of fluency), but particularly the ability to control attention during formulation and monitoring.

Along the same lines, Rosen and Engle (1997) provided evidence that individuals with higher working memory capacity tend to be more able to engage in self-monitoring, which may explain why participants with higher working memory capacity were the ones producing fewer errors and more error free clauses. 
In the area of task-based planning research, fluency, accuracy, and complexity are claimed to compete for learners' limited attentional resources, which leads to trade-off among these aspects of performance (SKEHAN, 1996, 1998; FOSTER \& SKEHAN, 1996; MEHNERT, 1998; YUAN \& ELLIS, 2003). In other words, because attentional resources are limited, it is unlikely that learners will sustain simultaneous high levels of performance in terms of fluency, accuracy, and complexity.

Bearing that in mind, it seems reasonable to argue that Skehan's proposal of attentional trade-offs among fluency, accuracy, and complexity in the context of learners' limited attentional resources is compatible with Engle's attentional view of working memory capacity. Most studies on planning have shown trade-off effects among the goals of fluency, accuracy, and complexity. The body of research results tends to show that fluency and complexity tend to improve at the expense of accuracy (MEHNERT, 1998).

Results of the present study show that under spontaneous conditions, there are significant correlations between working memory and accuracy in the performance of the control group. Possibly, greater accuracy was achieved by higher spans at the expense of fluent and complex speech production. As previously stated, most planning studies provide evidence that under planned conditions, fluent and complex speech are achieved at the expense of accurate speech. However, performing under a spontaneous condition tends to be more difficult for most learners and, thus, it is possible that learners will focus on one aspect of L2 speech at the expense of others.

Possibly, performing the tasks under spontaneous condition was too difficult, and may have led learners to some degree of discomfort or nervousness. Participants of the present study reported that performing tasks under the spontaneous condition was difficult. The following questionnaire excerpts illustrate learners' voices reporting the difficulties they faced:

\footnotetext{
Excerpts

"It was very difficult for me because I didn't know what to say" (p29)

"It was difficult...I couldn't elaborate a good story" (p6)

"It was difficult to create a story as you tell it at the same time" (p27)
}

In addition to that, learners also reported being nervous when performing the first narrative task, as the following excerpts illustrate:

Excerpts

"It was very difficult to me to tell a story immediately after looking at the because I'm not confident in my English, in fact, I know I still have a bad English" (p02) 
"I guess it was Ok, the big problem was that I got too scared and it didn't get the way I really wanted, but that's okay" (p25)

"I was a little nervous and at this point I forgot vocabulary, simple vocabulary, deu branco" (p09)

In the realm of affective/emotional variables, research has shown that anxiety may affect performance when a task is hard or when performance is under evaluation (LEE, 1999). The performance of the tasks under spontaneous condition may have led to some degree of anxiety from the part of the learners since they reported being nervous or worried about task performance. Research has shown that anxiety may lead learners to engage in negative internal dialogues or worrisome thoughts about themselves or about their performance, and these thoughts may actually interfere with working memory performance because some portion of capacity is directed at such thoughts (EYSENCK, 1992). Possibly, working memory capacity correlated with only one aspect of performance under spontaneous condition because worrisome thoughts may have been at play.

Klein and Boals (2001) claim that stressful and worrisome thoughts work as distracters that need to be inhibited so that attention can be maintained on the task being performed. Likewise, Unsworth, Heitz and Engle (2005) claim that individuals who differ in working memory capacity will also differ in the capacity to inhibit thoughts called to mind by stress and task manipulations. In other words, working memory capacity is related to the ability to inhibit unwanted thoughts. Perhaps, higher spans were better able to inhibit such unwanted thoughts during performance; thus, correlations between working memory capacity and L2 performance could emerge, at least for one aspect of performance.

Mizera (2006) also reported lack of correlations between working memory and some aspects of L2 speech performance. In his view, the complexities involved in L2 speech performance may involve factors other than working memory capacity. He claims that personal and affective factors may also play a role in L2 speech.

Interestingly, participants of the pilot study (GUARÁ-TAVARES, 2009) also reported some discomfort and difficulties when performing the narrative tasks under spontaneous conditions. In Guará-Tavares (2009), there were no correlations at all between working memory and L2 performance in task under spontaneous conditions. Thus, one question which merits to be addressed is: Why task difficulty prevented the emergence of individual differences in working memory under spontaneous conditions for all performance aspects in Guará-Tavares (2009) but 
still yielded individual differences in working memory for at least one aspect of performance in the present study?

In the attempt to answer the question just posed, I think it is important to bring the distinction between task complexity and task difficulty into play. Although, task difficulty and task complexity mean the same in Cognitive Psychology, they are slightly different in SLA. According to Robinson (2001), the factors contributing to task complexity are related to design features, such as 'here-and-now' or 'thereand-then', and planning or no planning. Robinson (2001) emphasizes that "these factors need to be distinguished from the learner factors contributing to task difficulty" (p. 295). Task difficulty is related to learners' perceptions of the task and may be determined by affective factors such as anxiety and motivation, and also by ability factors such as aptitude and proficiency (ROBINSON, 2001).

In this sense, it is possible to manipulate task complexity, as I have attempted to do in the present study and in the pilot study (GUARÁ-TAVARES, 2009) by using 'there-and-then' tasks so that individual differences in working memory capacity would be likely to emerge. However, "affective variables contributing to task difficulty are hard, or impossible to diagnose in advance" (ROBINSON, 2001, p. 295), as it is the learner who asserts it.

Bearing the distinctions between task complexity and task difficulty in mind, it seems plausible to argue that the 'there-and-then' narrative tasks may have been extremely difficult for participants of the pilot study, thus, individual differences in working memory capacity did not emerge because learners may have performed the tasks beyond the limits of their cognitive resources. On the other hand, the same 'there-and-then' tasks may have been difficult for participants of the present study but not to the same degree as for learners of the pilot study; thus, individual differences in working memory capacity could emerge, at least concerning one aspect of L2 performance, that is, accuracy for the control group and fluency for the experimental group.

Researchers claim that for individual differences in working memory capacity to emerge, the task under performance has to be difficult (FORTKAMP, 2000; CONWAY ET AL., 2005; JUST \& CARPENTER, 1992; TOMITCH, 1996). Tasks which are either too easy or too difficult do not seem to reveal individual differences in working memory capacity.

Up to this point, I have discussed results of the correlations between working memory capacity and L2 speech performance under spontaneous condition. Now I turn to the discussion on the relationship between working memory and L2 speech performance under planned condition. 
Under planned condition, results displayed in Table 2 revealed significant correlations between working memory capacity and fluency as well as significant correlations between working memory capacity and complexity. Correlations between working memory capacity and accuracy only approached significance. Taken together, these correlations show that under planning conditions higher span individuals are the ones whose speech performance is significantly more fluent and complex.

Interestingly, under planned condition individual differences in working memory were related to more aspects of L2 performance when compared to the no planning condition. It could be argued that planning made the task more manageable, that is to say, performing the task under planned condition was not as difficult performing it under no planning condition. It seems that the task was difficult enough for individual differences in working memory capacity to emerge more fully.

Recall that fluent speech involves continuous speech in real time communication, which implies some degree of automaticity and involves effective coordination of all the stages of speech- (e.g., conceptualization, message construction, formulation, monitoring, and articulation). Fluent speech was operationalized in terms of temporal measures, real time communication. Thus, I am inclined to believe that what seems to account for the relationship between working memory and fluency is not concerned mainly with monitoring and articulation, but particularly with the ability to control attention during conceptualization, message construction, and formulation effectively, so as to allow continuous speech, in real time communication, to take place.

Moreover, the benefits of planning may also rely on the ability to implement what was planned into performance (ORTEGA, 2005). In other words, the benefits of planning may also draw upon the ability to retrieve what was planned and implement it into online performance. Individual differences in working memory capacity reflect differences in the ability to retrieve information from long term memory (ROSEN \& ENGLE, 1997; UNSWORTH \& ENGLE, 2007). Therefore, it may be that higher memory spans were more able to retrieve what was planned into real time performance and, thus, achieved higher fluency.

Under planned condition, besides the significant correlations between working memory capacity and fluency, there were also significant correlations between working memory capacity and complexity. According to Skehan (1996), complexity is related to restructuring and regards "the process by which the interlanguage system becomes more complex, elaborated and structured" (p.47). 
Complexity implies risk taking performance in the attempt to produce more elaborated, cutting edge language.

As previously explained in the Review of the Literature, Skehan (1996, 1998) postulates that, in L2 learning and use, learners draw upon a dual-mode processing system, which encompasses the rule-based and the exemplar-based systems. Complex language production implies drawing upon the rule-based system, which prioritizes analyzability, leads to a form-oriented organization that regards development in terms of change and complexity and, according to which, interlanguage development is the outcome of restructuring.

Recall that Feldman-Barrett et al. (2004) also acknowledge the coexistence of two modes of processing. The associative (exemplar) mode functions on the bases previous existing representations in which information is processed automatically. Thus, associative processing is not under the constraints of limitations in working memory capacity. Rule-based processing, on the other hand, involves symbolic representations, concerns incorporating new or inconsistent information into preexisting representations and, thus, is more harshly under the constraints of attentional control.

Pre-task planning releases the processing load and allows learners to access the upper limits of their interlanguage in the attempt to produce more complex and elaborate language (CROOKES, 1989). Since complex speech involves drawing upon the rule-based system and since rule-based processing is under the constraints of attentional control, this may explain why higher spans were the ones who achieved more complex speech under planning condition.

Based on what has been said, what accounts for the correlations between working memory capacity and complex L2 speech? The ability to control attention in the Speaking Span Test, which requires learners to activate words and maintain these words activated and accessible for recall while processing sentences containing the words recalled, parallels the ability to control attention in rulebased processing necessary for complex language production. In complex language production, learners need to activate preexisting representations and maintain them activated and accessible while processing inconsistent representations (e.g. cutting edge language the learner is not sure about) and incorporate this edging information into preexisting representations. According to Feldman-Barrett et al. (2004), rule-based processing is under the constraints of working memory capacity limitations, which may explain why higher spans produced more complex language.

It is important to highlight that these correlations between working memory and performance under planned condition indicate that the higher the memory, the higher 
the fluency and the complexity. Nevertheless, these correlations do not reveal whether the differences between the performance of lower and higher spans were significant. This issue has been addressed in my ongoing research and will be published elsewhere.

\section{FINAL REMARKS}

The overall results of the present study showed that individual differences in working memory capacity emerge in L2 speech performance under spontaneous as well as under planned conditions. However these results are to be seen as modest and suggestive rather than conclusive due to the several limitations of the study. First, the study is limited concerning sample size. Although 50 participants may be considered a reasonable number in the realm of language learning, it is considered fairly small in the field of working memory research. Second, the analysis focused solely upon correlational analyses. Third, the study focused on learners from the intermediate level only.

Despite its limitations, the present study suggests that individual differences in working memory capacity mediates L2 speech performance in spontaneous as well as in planned conditions. In this sense, the present study represents a step beyond the speculative notion that there are trade off effects among fluency, accuracy, and complexity due to learners' limited attentional resources (FOSTER \& SKEHAN, 1996; MENHERT, 1998, among others). Further research is needed in order to understand the role of working memory capacity in L2 speech performance under spontaneous and planned conditions.

\section{REFERENCES}

CONWAY, A. R. A., KANE, M. J., BUNTING, M. F., HAMBRICK, D. Z., WILHELM, O., \& ENGLE, R. W. (2005). Working memory span tasks: A methodological review and user's guide. Psychonomic Bulletin and Review, 12 (5), 769-786.

CROOKES, G. (1989). Planning and interlanguage variation. Studies in Second Language Acquisition, 11, 367-383.

DANEMAN, M. (1991). Working memory as a predictor of verbal fluency. Journal of Psycholinguistic Research, 20, 445-464. 213

DANEMAN, M., \& GREEN, I. (1986). Individual differences in comprehending and producing words in context. Journal of Memory and Language, 25, 1-18. 
DE BOT, K. (1992). A bilingual production model: Levelt's speaking model adapted. Applied Linguistics, 13, 1-24.

D'ELY, R. (2004). An investigation of learners' metacognitive processes of planning and rebearsal as catalysts of interlanguage development. Unpublished manuscript.

ELLIS, R. (1987). Interlanguage variability in narrative discourse: Style shifting in the use of the past tense. Studies in Second Language Acquisition, 9, 12-20. (2003). Task-based language teaching and learning. Oxford: Oxford

University Press.

. (2005). Planning and task-based performance: Theory and research. In R. Ellis (Ed.), Planning and task performance in a second language (pp.03-34). Amsterdam and Philadelphia: John Benjamins.

ELLIS, R. YUAN, F. (2005). The effects of careful within-task planning on oral and written task performance In R. Ellis (Ed.), Planning and task performance in a second language (pp.03-34). Amsterdam and Philadelphia: John Benjamins.

ENGLE, R. W., KANE, M. J., \& TUHOLSKI, S. W. (1999). Individual differences in working memory capacity and what they tell us about controlled attention, general fluid intelligence and functions of the prefrontal cortex. In A. Miyake \& P. Shah (Eds.) Models of working memory: mechanisms of active maintenance and executive control. New York: Cambridge University Press, pp.102-134.

EYSENCK, M. W. (1992). Anxiety: The cognitive perspective. London: Lawrence Erlbaum.

FELDMAN-BARRETT, L., TUGADE, M. M., \& ENGLE, R. W. (2004). Individual differences in working memory capacity and dual-process theories of the mind. Psychological Bulletin, 130, 553-573.

FORTKAMP, M. B. M. (1999). Working memory capacity and aspects of L2 speech production. Communication and Cognition, 32, 259-296.

(2000). Working memory capacity and L2 speech production: An exploratory study. Unpublished Ph.D. dissertation, Federal University of Santa Catarina, Florianópolis, Santa Catarina, Brazil.

. (2003). Working memory capacity and fluency, accuracy, complexity, and lexical density in L2 speech production. Fragmentos, 24, 69-104.

FOSTER, P. \& SKEHAN, P. (1996). The influence of planning and task type on second language performance. Studies in Second Language Acquisition, 18, 299-323.

GUARÁ-TAVARES, M. G. (2009). The relationship among pre-task planning, working memory capacity and L2 speech performance: a pilot study. Linguagem \& Ensino (UCPel), v. 12, p. 165-194, 2009

. (2011). Pre-task planning, working memory capacity and L2 speech performance. Organon, 51, p. 255-266,

HAMBRICK, D. Z., \& ENGLE, R. W. (2003). The role of working memory in problem solving. In J. E. Davidson \& R. J. Sternberg (Eds.), The psychology of problem solving (pp. 176 206). London: Cambridge Press. 
JUST, M. A., \& CARPENTER, P. A. (1992). A capacity theory of comprehension: Individual differences in working memory. Psychological Review, 99, 122-149.

KANE, M. J., CONWAY, A. R. A., HAMBRICK, D. Z, \& ENGLE, R. W. (2007). Variation in working memory capacity as variation in executive attention and control. In $\mathrm{A}$. R. A. CONWAY, C. JARROLD, M. J. KANE, A. MIYAKE, \& J. N. Touse (Eds.), Variation in working memory (pp. 21-48). New York: Oxford University Press.

KAWAUCHI, C. (2005). The effects of strategic planning on the oral narratives of learners with low and high intermediate levels of L2 proficiency. In R. Ellis (Ed.), Planning and task performance in a second language (pp. 143-164). Amsterdam and Philadelphia: John Benjamins.

KLEIN, K., \& BOALS, A. (2001). The relationship of life events stress and working memory capacity. Applied Cognitive Psychology, 15, 565-579.

LEE, J. Y. (1999). Test anxiety and working memory. The Journal of Experimental Education, 67 (3), 218-223.

LEVELT, W. J. M. (1989). Speaking: From intention to articulation. Cambridge, MA: MIT Press.

MCNAMARA, D. S., \& SCOTT, J. L. (2001). Working memory capacity and strategy use. Memory \& Cognition, 29 (1), 10-17.

MEHNERT, U. (1998). The effects of different lengths of time for planning on second language performance. Studies in Second Language Acquisition, 20, 83-108.

MIZERA, G. J. (2006). Working memory and L2 oral fluency. Unpublished Ph.D. dissertation, University of Pittsburgh, Pennsylvania, The United States of America.

ORTEGA, L. (1999). Planning and focus on form in L2 oral performance. Studies in Second Language Acquisition, 21, 109-148.

(2005). What do learners plan? Learner-driven attention to form during pretask planning. In R. Ellis (Ed.), Planning and task performance in a second language (pp. 77-110). Amsterdam and Philadelphia: John Benjamins.

POULISSE, N. (1999). Language production in bilinguals. In A. M. B. de Groot \& J. K. Kroll (Eds.), Tutorials in bilingualism: Psycholinguistic perspectives (pp. 201-225). Mahwah, NJ: Lawrence Erlbaum.

ROBINSON, P. (1995). Task complexity and second language narrative discourse. Language Learning, 45 (1), 99-140.

ROBINSON, P. (2001). Task complexity, cognitive resources, and syllabus design: A triadic framework for examining task influences on SLA. In P. Robinson (Ed.), Cognition and second language instruction (pp. 287-318). Cambridge: Cambridge University Press.

ROSEN, V. M., \& ENGLE, R. W. (1997). The role of working memory capacity in retrieval. Journal of Experimental Psychology, 126 (3), 211-227.

SANGARUN, J. (2005). The effects of focusing on meaning and form in strategic planning. In R. Ellis (Ed.), Planning and task performance in a second language (pp. 111-142). Amsterdam and Philadelphia: John Benjamins. 
SCHIMDT, R. (1990). The role of consciousness in second language learning. Applied Linguistics, 11, 129-158.

SKEHAN, P. (1996). A framework for the implementation of task-based instruction. Applied Linguistics, 17 (1), 38-62. . (1998). A cognitive approach to language learning. Oxford: Oxford University Press. Cognition and second language instruction (pp. 183-205). New York: Cambridge University Press.

SKEHAN, P., \& FOSTER, P. (2005). Strategic and on-line planning: The influence of surprise information and task time on second language performance. In R. Ellis (Ed.), Planning and task performance in a second language (pp. 193-218). Amsterdam and Philadelphia: John Benjamins.

TAVAKOLI, P., \& SKEHAN, P. (2005). Strategic planning, task structure, and performance testing. In R. Ellis (Ed.), Planning and task performance in a second language (pp.239-276). Amsterdam and Philadelphia: John Benjamins.

TOMITCH, L. M. B. (1996). Individual differences in the text organization perception and working memory capacity. Revista da ANPOLL, 2, 71-93.

UNSWORTH, N., \& ENGLE, R. W. (2007). The nature of individual differences in working memory capacity: Active maintenance in primary memory and controlled search from secondary memory. Psychological Review, 114, 104-132.

UNSWORTH, N., HEITZ, R. P., \& ENGLE, R. W. (2005). Working memory capacity in hot and cold cognition. In R. W. Engle, G. Sedek, U. Hecker, \& D. N. McIntosh (Eds.), Cognitive limitations in aging and psychopathology (pp. 19-43). New York: Cambridge University Press.

VANPATTEN, B. (1990). Attending to content and form in the input: An experiment on consciousness. Studies in Second Language Acquisition, 12, 287-301. . (1996). Input processing and grammar instruction. Norwood, NJ: Ablex.

YUAN, F., \& ELLIS, R. (2003). The effects of pre-task planning and on-line planning on fluency, complexity and accuracy in L2 monologic oral production. Applied Linguistics, $24,1-27$.

Recebido: 27/07/2012

Aceito: 11/04/2013 
